\title{
Comparison of Maximum Phonation Duration and S/Z Ratio in Individuals with Asthma, Tuberculosis and Clinically Normal Voice
}

\author{
Susmita Shrestha and Anil Kumar Adhikari
}

Department of ENT-HNS, Tribhuwan University Teaching Hospital, Maharajgunj, Kathmandu, Nepal

\begin{abstract}
Introduction: The ability of a person to phonate a sound gets affected in different laryngeal and respiratory pathology which can be measured by the help of two measure called as Maximum Phonation Duration (MPD) and $S / Z$ ratio. These help to assess the efficiency of respiratory and phonatory system. The aim of this study is to measure the MPD and S/Z ratio in Normal, Tuberculosis and Asthma group patient.

Methods: The participant included Normal, Asthma and Tuberculosis patients where the recording was made in a quiet room with the help of PRAAT software and the participant were asked to sustain phonation of sound on single breath. Analysis was done with helps of SPSS version 25.0.

Results: There was a significant difference noted in MPD of /a/, / i/, /u/ sound between control and experimental group. MPD were significantly shorter in Asthma and Tuberculosis group compared to Normal group with no significant difference in $\mathrm{S} / \mathrm{Z}$ ratio.

Conclusions: Maximum Phonation Duration is more reduced in Asthma and Tuberculosis patient compared to Normal group which indicate Asthma and Tuberculosis patient has to put more effort to phonate a sound and breath support therapy might help in correction.
\end{abstract}

Key words: articulatory; phonation; voice; vowels

Correspondence: Susmita Shrestha. Department of ENT-HNS, Tribhuwan University Teaching Hospital, Maharajgunj, Kathmandu, Nepal. E-mail:sushmitaiom@gmail.com

DOI: http://dx.doi.org/0.3126/mjsbh.v18i2.24089

Submitted on: 2019-03-15

Accepted on: 2019-06-14

This work is licensed under creative common license:

http://creativecommons.org/licenses/by-nc-nd/4.0/ C MJSBH 2019 


\section{INTRODUCTION}

Phonation is the vibration of vocal fold produced by the expiratory airflow flow from lungs. ${ }^{1}$ The ability to sustain phonation get reduced in different pathological conditions which can be measured by sustaining a phonation of sound on single breath, called as Maximum Phonation Duration (MPD). ${ }^{2}$ The MPD may vary considerably between people and age group and also some pathological cases. ${ }^{3}$ Short phonation time reflects inefficiency of phonatory and respiratory system. ${ }^{4}$ This can be used as an assessment and treatment tool to rule out pathology and to monitor the progress during and post treatment of voice disorders. ${ }^{5}$ Values below 10 second are considered altered. ${ }^{6}$ Low MPD values are related to laryngeal pathology. ${ }^{7}$ During respiration, the respiratory muscles function increases to overcome the obstruction of air flow. ${ }^{8}$ Respiratory diseases may have difficulty in phonation due to compromise in the lungs ability to expand and contract. ${ }^{9} \mathrm{~S} / \mathrm{Z}$ ratio is another measure of phonation time where the maximum sustained time of $/ \mathrm{S} /$ is divided by the maximum sustained time of $/ Z / .^{10}$ Altered value in MPD also indicate poor coordination of respiratory muscles leading to fatigue and breathlessness. ${ }^{6}$ Published research studying analysis of voice to compare the MPD and $S / Z$ ratio of population with respiratory disorders and clinically normal group is scanty. The aim of this study is to compare the MPD and S/Z ratio in individuals with clinically normal voice, tuberculosis and asthma patient.

\section{METHODS}

This is a prospective observational cross-sectional study done in District hospital of Sarlahi, Nepal from April 2016 to November 2016. The samples were collected as a convenient sampling with set target of 20 numbers of samples on each group of Normal, Asthma and Tuberculosis within three months duration from April 2016. All together 60 convenient samples were taken into study after the verbal consent of the participants and approved by the Institutional Review Board of the institution. The participants were divided into two groups i.e. Normal group as a control group and Asthma and Tuberculosis as the experimental group. The experimental group participants were under medication for three months. The testing was conducted in a quiet room and the recording was done through the PRAAT software version 5.1.37 (Boersma and Weenick, 2009). The participants were asked to phonate the vowel $/ \mathrm{a} / / \mathrm{i} / / \mathrm{u} / / \mathrm{s} / / \mathrm{z} /$ individually in a single breath as long as possible. The phonation task was demonstrated before the participants phonated. All together three trials were taken for all these sound prolongation and MPT was calculated for three vowels $/ \mathrm{a} / / \mathrm{i} / / \mathrm{u} /$ for the duration of how long it is prolonged and $\mathrm{S} / \mathrm{Z}$ ratio was calculated for sound $/ \mathrm{s} /$ and $/ \mathrm{z} /$ by dividing the duration of $/ \mathrm{s} /$ phonation by the duration of $/ \mathrm{z} /$

Table 1. Maximum Phonation Duration and S/Z Ratio Study

\begin{tabular}{|c|c|c|c|c|c|c|c|c|}
\hline \multirow[t]{3}{*}{ Groups } & \multicolumn{6}{|c|}{ MPD } & \multirow[b]{3}{*}{ Mean \pm SD } & \multirow[b]{3}{*}{ p-value } \\
\hline & \multicolumn{2}{|l|}{$\mathbf{a}$} & \multicolumn{2}{|l|}{ i } & \multicolumn{2}{|c|}{$\mathbf{u}$} & & \\
\hline & Mean \pm SD & p-value & Mean \pm SD & p-value & Mean \pm SD & p-value & & \\
\hline $\begin{array}{l}\text { Normal } \\
\text { Asthma }\end{array}$ & $\begin{array}{l}14.41 \pm 1.97 \\
7.18 \pm 3.14\end{array}$ & $<0.001$ & $\begin{array}{l}15.65 \pm 3.94 \\
7.29 \pm 3.33\end{array}$ & $<0.001$ & $\begin{array}{l}15.39 \pm 3.31 \\
6.70 \pm 3.12\end{array}$ & $<0.001$ & $\begin{array}{l}0.96 \pm 0.16 \\
0.96 \pm 0.27\end{array}$ & 0.97 \\
\hline $\begin{array}{l}\text { Normal } \\
\text { Tuberculosis }\end{array}$ & $\begin{array}{l}14.41 \pm 1.97 \\
11.27 \pm 4.18\end{array}$ & 0.004 & $\begin{array}{l}15.65 \pm 3.94 \\
13.15 \pm 5.79\end{array}$ & 0.12 & $\begin{array}{l}15.39 \pm 3.31 \\
12.90 \pm 5.13\end{array}$ & 0.08 & $\begin{array}{l}0.96 \pm 0.16 \\
1.10 \pm 0.26\end{array}$ & 0.04 \\
\hline $\begin{array}{l}\text { Asthma } \\
\text { Tuberculosis }\end{array}$ & $\begin{array}{l}7.18 \pm 3.14 \\
11.27 \pm 4.18\end{array}$ & 0.001 & $\begin{array}{l}7.29 \pm 3.33 \\
13.15 \pm 5.79\end{array}$ & $<0.001$ & $\begin{array}{l}6.70 \pm 3.12 \\
12.90 \pm 5.13\end{array}$ & $<0.001$ & $\begin{array}{l}0.96 \pm 0.27 \\
1.10 \pm 0.26\end{array}$ & 0.08 \\
\hline
\end{tabular}




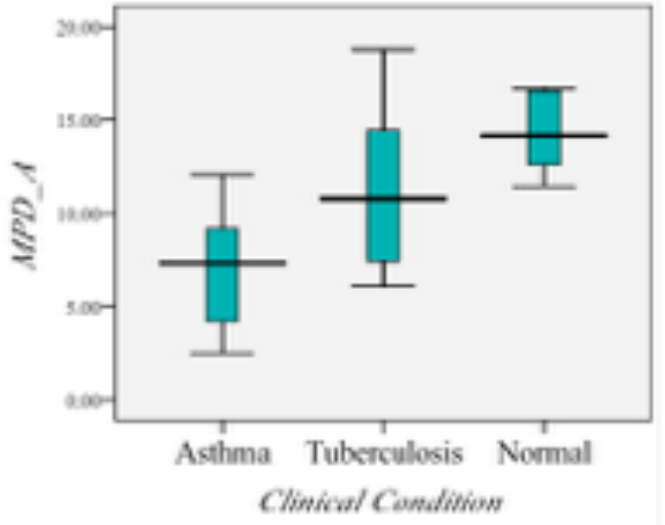

Figure 1. MPD_a for Asthma, Tuberculosis and Normal

phonation. Categorical variables were summarised using frequencies and percentages and continuous variables were used mean and standard deviation. Comparisons of MPD between Asthma with Normal, Tuberculosis with Normal and Asthma with Tuberculosis were done using ANOVA. As there were multiple comparisons, $p<0.02$ was considered as statistically significant based on Bonferroni correction criteria. Analysis was done using SPSS v 25.0.

\section{RESULTS}

Out of 60 total participants, there were 20 each on Normal, Asthma and Tuberculosis group. The age range of the subjects was from 25-60 years with the mean age of 38 years. The mean of MPD /a/ for the groups Normal, Asthma and Tuberculosis were found to be $14.41,7.18$ and 11.27 respectively. The

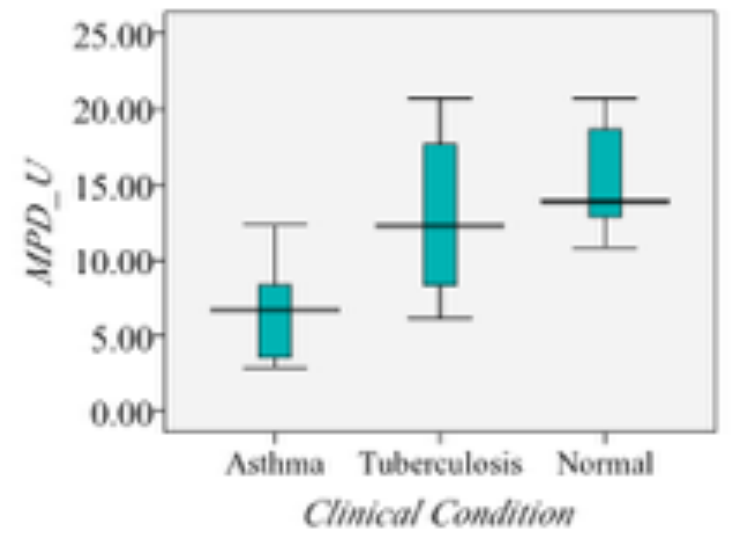

Figure 3. MPD_u for Asthma, Tuberculosis and Normal

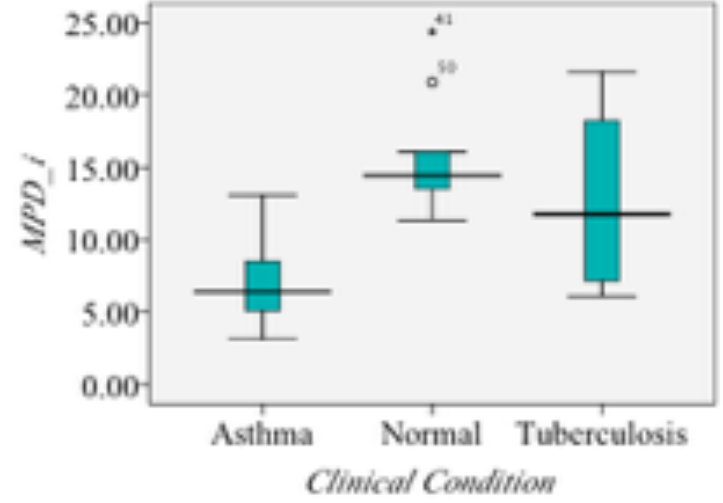

Figure 2. MPD_i for Asthma, Tuberculosis and Normal

mean of MPD /i/ for the groups Normal, Asthma and Tuberculosis were found to be 15.65, 7.29 and 13.15 respectively. The mean of MPD /u/ for the groups Normal, Asthma and Tuberculosis were found to be $15.39,6.70$ and 12.90 respectively. Similarly, the mean of $S / Z$ ratio for the groups Normal, Asthma and Tuberculosis were found to be $0.96,0.96$ and 1.10 respectively. The mean difference results of the study is shown in table 1 and figures 1, 2, 3 and 4 .

\section{DISCUSSION}

Asthma is a chronic airway disease. It is characterised by airway inflammation and airflow obstruction. ${ }^{11}$ Inflammation leads to airway thickening. ${ }^{12}$ The clinical manifestation include cough, wheezing and chest tightness. ${ }^{13}$ The results

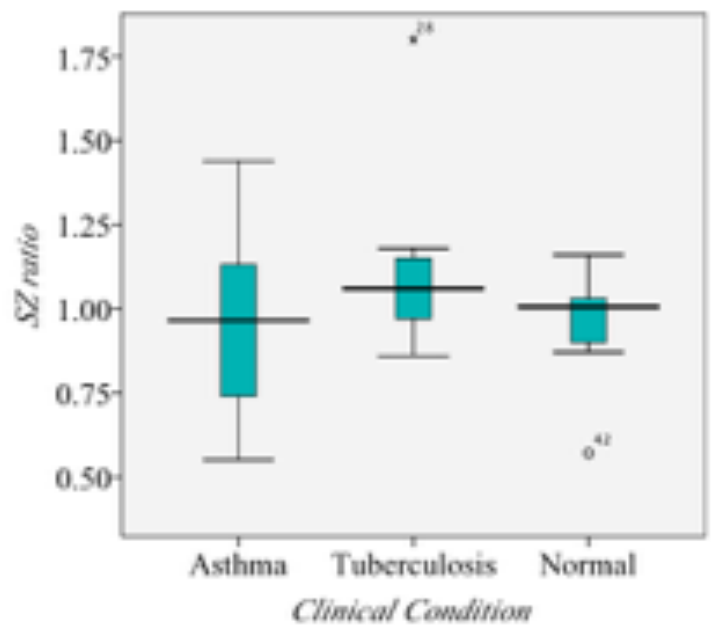

Figure 4. S/Z for Asthma, Tuberculosis and Normal 
of this study revealed that the control group can sustain the vowels /a/ $/ \mathrm{i} /$ and $/ \mathrm{u} /$ sound much longer than the experimental group. The mean difference of MPD /a/ between the groups Normal and Asthma is 7.23 which is statistically significant $(p<0.001)$. The mean difference of MPD /a/ in the groups Normal and Tuberculosis is 3.14 which also is statistically significant $(\mathrm{p}=0.004)$. Similarly, the mean difference for MPD /a/ is 4.09 between Tuberculosis and Asthma with statistically significance $(p=0.001)$. The mean difference of MPD /i/ between Normal and Asthma is 8.36 and between Tuberculosis and Asthma is 5.86 which is statistically significant $(p<0.001)$. The mean difference of MPD / $\mathrm{u}$ / between Normal and Asthma is 8.69 and between Tuberculosis and Asthma is 6.20 which is statistically significant $(p<0.001)$. $\mathrm{S} / \mathrm{Z}$ ratio is another measure for examining the individual's articulatory and phonatory capabilities of speakers. The results of the $S / Z$ ratio for both the control group and experimental group show that the mean $\mathrm{S} / \mathrm{Z}$ ratio of the two groups is quite close. There was no statistically significant difference between the $S / Z$ ratio of control and experimental groups. The results of this study is supported by the study done on Parkinson's diseases to assess MPT and $S / Z$ ratio indicating no significance difference on $s / z$ ratio but difference was noted on MPT indicating that MPT is more reliable measure to assess respiratory function compared to $\mathrm{S} / \mathrm{Z}$ ratio. ${ }^{14}$ Asthma and tuberculosis are very common respiratory diseases in general population nowadays, which impairs the normal respiratory pattern and hence also affects the speech production. The goal of this study was to compare the maximum phonation time and $S / Z$ ratio across the groups. However, $S / Z$ ratio did not statistically distinguish the experimental group from controls, but the experimental group performed statistically poorer on maximum sound prolongation task than controls. They were relatively unable to sustain sound as long as the control. Few studies have investigated the prevalence of phonatory and aerodynamic measures in asthma and control groups. ${ }^{15}$ Ihre et al. in his study reported dysphonia in $80 \%$ of cases. Govindaiah et al. reported dysphonia in $46.4 \%$ of patients with asthma. ${ }^{16}$ The results of this study conflict with the study done by Abdul et al which indicated no significant differences in MPD value in normal and asthma patient. ${ }^{17}$ Also the result of this study indicated that experimental group had to put more effort to phonate compared to normal group. The prevalence of reduced phonation time in asthma and tuberculosis group can be explained on several bases: one is impaired expiration in both asthma and tuberculosis and also the restricted breathing which affects the phonation. Several studies have documented the importance of breathing as power supply to voice production and ability to sustain phonation. ${ }^{18}$ Lung function influences voice and lung volume can markedly affect phonation. Iwarsson et al. demonstrated that with decreased lung volume, the closed quotient increases, while the subglottic pressure, peak to peak flow amplitude and leakage across the glottis decrease. ${ }^{19}$ Ruas et al found improved maximum phonation duration and $\mathrm{S} / \mathrm{Z}$ ratio in patient with tuberculosis after speech therapy. ${ }^{20}$ Fagundes et al. found improved maximum phonation duration in patient with tuberculosis by four second following speech therapy. ${ }^{21}$ According to the literature, pulmonary tuberculosis can cause a reduction in loudness since the expiratory air volume is the source of the aerodynamic energy for phonation. ${ }^{22}$ Ruas et al. also reported improved voice quality and maximum phonation time and Improved $S / Z$ ratio in patient with tuberculosis following voice therapy. ${ }^{20}$ In this study, there was a predominance of normal group over the asthma and tuberculosis group with respect to all variables compared. Lack of confounding factors like age, sex and severity of disease are mentioned as the limitations of this study.

\section{CONCLUSIONS}

Reduction in maximum phonation duration is more prevalent in asthma and tuberculosis compared to control normal group. Asthmatic patient had to put more effort than normal and tuberculosis patient to phonate a sound. So this might explore the necessity of breath support therapy along with 
voice therapy in asthmatic and tuberculosis patients.

\section{ACKNOWLEDGEMENTS}

We would like to thank Dr Yogendra Amatya for the continuous guidance and motivation to complete the study.

To cite this article: Shrestha $\mathrm{S}$, Adhikari AK. Comparison of maximum phonation duration and $\mathrm{S} / \mathrm{Z}$ ratio in individuals with asthma, tuberculosis and clinically normal voice. MJSBH. 2019;18(2):16-21.

Conflict of Interest: None declared

\section{REFERENCES}

1. Boone D, McFarlane S. The Voice and Voice Therapy. 5th ed. Prentice Hall College Div; 1993.

2. Maslan J, Leng X, Rees C, Blalock D, Butler S. Maximum Phonation Time in Healthy Older Adults. J Voice. 2011;25(6):709-713.

DOI: $10.1016 /$ j.jvoice.2010.10.002

3. Hirano M, Koike Y, von Leden H. Maximum phonation time and air usage during phonation. Folia Phoniatrica et Logopaedica. 1968;20(4):185-201.

Available from: https://www.karger.com/Article/Abstract/263198\#

4. Pearl Solomon N, Garlitz S, Milbrath R. Respiratory and laryngeal contributions to maximum phonation duration. J Voice. 2000;14(3):331-340.

DOI: $10.1016 / \mathrm{S} 0892-1997(00) 80079-\mathrm{X}$

5. Cassiani R, Aguiar-Ricz L, Santos C, Martinez J, Dantas R. Glottal competence in chronic obstructive pulmonary disease. Audiology-Communication Research. 2013;18(3).

DOI: $10.1590 / \mathrm{S} 2317-64312013000300003$

6. Englert M, Mesquita L, Azevedo R. Comparison of methods to extract the maximum phonation duration in individuals without vocal complaints. Rev. CEFAC. 2014;16(5).

DOI: $10.1590 / 1982-0216201414713$

7. Cielo CA, Gonçalves BF, Lima JP, Christmann MK. Maximum phonation time of /a/, maximun phonation time predicted and respiratory type in adult women without laryngeal disorders. Revista CEFAC. 2015;17(2):358-63.

DOI: $10.1590 / 1982-021620152414$

8. Donahoe M, Rogers R, Wilson D, Pennock B. Oxygen Consumption of the Respiratory Muscles in Normal and in Malnourished Patients with Chronic Obstructive Pulmonary Disease. American Review of Respiratory Disease. 1989;140(2):385-91.

DOI: $10.1164 / \mathrm{ajrccm} / 140.2 .385$

9. Binazzi B, Lanini B, Bianchi R, Romagnoli I, Nerini M, Gigliotti F, et al. Breathing pattern and kinematics in normal subjects during speech, singing and loud whispering. Acta Physiologica. 2006;186(3):233-46.

DOI:10.1111/j.1748-1716.2006.01529.x

10. Eckel F, Boone D. The S/Z Ratio as an Indicator of Laryngeal Pathology. J Speech Hear Disord. 1981;46(2):147-9. DOI: $10.1044 /$ jshd.4602.147

11. Manuyakorn W, Howarth PH, Holgate ST. Airway remodelling in asthma and novel therapy. Asian Pac J Allergy Immunol. 2013;31:3-10.

12. Kudo M, Ishigatsubo Y, Aoki I. Pathology of asthma. Frontiers in Microbiology. 2013;4. DOI:10.3389/fmicb.2013.00263

13. GINA (2012). Global strategy for asthma management and prevention [Internet]. 2012 Available from: https://ginasthma.org/wp-content/uploads/2019/01/2012-GINA.pdf 
14. Lu F, Presley S, Lammers B. Efficacy of Intensive Phonatory-Respiratory Treatment (LSVT) for Presbyphonia: Two Case Reports. J Voice. 2013;27(6):11-23.

DOI:10.1016/j.jvoice.2013.06.006

15. Ihre E, Zetterström O, Ihre E, Hammarberg B. Voice problems as side effects of inhaled corticosteroids in asthma patients - a prevalence study. J Voice. 2004;18(3):403-14.

DOI:10.1016/j.jvoice.2003.05.003

16. Govindaiah RC, Baldwin JL, Sanders GM. Incidence and potential etiologies of dysphonia in patients with allergies and/or asthma. J Allergy Clin Immunol. 2004;113(2):275. DOI: 10.1016/j.jaci.2004.01.464.

17. Hamdan AL, Ziade G, Kasti M, Akl L, Bawab I, Kanj N. Phonatory Symptoms and Acoustic Findings in Patients with Asthma: A Cross-Sectional Controlled Study. Indian J Otolaryngol Head Neck Surg. 2016;69(1):42-6. DOI: $10.1007 / \mathrm{s} 12070-016-1035-8$

18. Solomon NP, Garlitz SJ, Milbrath RL. Respiratory and laryngeal contributions to maximum phonation duration. J Voice. 2000;14(3):331-40. DOI: $10.1016 / \mathrm{S} 0892-1997(00) 80079-X$.

19. Iwarsson J, Thomasson M, Sundberg J. Effects of lung volume on the glottal voice source. J Voice. 1998;12(4): 424-33. DOI: $10.1016 / \mathrm{S} 0892-1997(98) 80051-9$.

20. Ruas AC, Rolla VC, de Araújo-Melo MH, Moreira JS, Valete-Rosalino CM. Vocal quality of patients treated for laryngeal tuberculosis, before and after speech therapy. J Laryngol Otol. 2010;124(11):1153-60. DOI: $10.1017 / \mathrm{S} 0022215110001106$.

21. Fagundes RC, Cury RI, Anelli-Bastos W, Silva L, Duprat A. Laryngeal tuberculosis: proposal of Speech-Language Pathology intervention in voice disorders following pharmacological treatment. Rev soc bras fonoaudiol. 2011; 16(1):99-103. DOI: $10.1590 / \mathrm{S} 1516-80342011000100018$

22. Yelken K, Guven M, Topak M, Gultekin E, Turan F. Effects of antituberculosis treatment on self assessment, perceptual analysis and acoustic analysis of voice quality in laryngeal tuberculosis patient. J Laryngol Otol. 2008; 122(4):378-82.

DOI: $10.1017 / \mathrm{S} 0022215107008961$ 